\title{
Fairy-wrens as a model system for studying cuckoo-host coevolution
}

\author{
N. E. Langmore \\ Research School of Biology, Australian National University, Canberra, ACT 0200, Australia. \\ Email: naomi.langmore@anu.edu.au
}

\begin{abstract}
Many malurids are major cuckoo hosts in Australia and provide an ideal opportunity to investigate cuckoo-host coevolution. Here, I (1) discuss why malurids provide a particularly tractable system for studies of cuckoo parasitism, (2) compare rates and patterns of parasitism across a range of malurid species, (3) discuss the evidence for coevolution between malurids and cuckoos and how studies of this system have advanced the study of coevolution and (4) suggest some possible directions for future research. Significantly, members of the Maluridae exhibit arguably the most advanced portfolio of defences against cuckoos of any avian brood parasite host yet discovered.
\end{abstract}

Received 10 September 2012, accepted 23 April 2013, published online 15 August 2013

\section{Introduction}

The interactions between brood parasites and their hosts provide an ideal model system for studies of coevolution (Rothstein 1990; Davies 2000). Brood parasites lay their eggs in the nests of hosts and then abandon their young to the host's care. In many parasitic cuckoos, the newly hatched parasite chick ejects the host eggs from the nest, becoming the sole occupant of the nest. The costs of parasitism to the host are high, in terms of the failure of their own reproductive attempt and the energetic expenditure and time lost in rearing the parasite. In the face of such high costs hosts evolve defences against parasitism, which in turn give rise to counter-adaptations in the parasite. The tight, sometimes even pair-wise, interactions between parasitic cuckoos and their hosts facilitate exploration of coevolutionary processes, because defences in hosts can be clearly attributed to a particular parasite species, and parasite counter-adaptations can often also be attributed to a single host species or genus (Rothstein 1990).

The interactions between the Maluridae and their primary parasite, Horsfield's Bronze-Cuckoo (Chalcites basalis), are one such coevolving system. Malurids are likely to have been coevolving with cuckoos for several million years (Brooker and Brooker 1996). As well as providing a classic example of brood parasite-host coevolution, there are several additional compelling reasons for studying cuckoo-host dynamics in the Maluridae. First, malurids possess several attributes that facilitate cuckoo research; they are a major cuckoo host in Australia (Brooker and Brooker 1989); they have readily accessible and easily located nests, and they occur at high densities in a wide range of habitats, including some urban areas. Second, parasitism rates can be very high, making this a tractable system for experimental work. Third, parasitism rates are highly variable, facilitating identification of the factors that predispose a population to parasitism. Finally, and most significantly, the coevolutionary interactions between fairywrens and cuckoos have evolved to a uniquely advanced stage, comprising a novel host defence to prevent cuckoos from laying in the nest, as well as unique adaptations in both hosts and cuckoos at the chick stage (see 'Coevolution between malurids and bronze-cuckoos' below).

\section{Brood parasitism in the Maluridae}

The Maluridae are hosts to several cuckoo species around Australia. By far the most common brood parasite of malurids is Horsfield's Bronze-Cuckoo, which favours fairy-wren hosts throughout Australia (Brooker and Brooker 1989). Parasitism by Horsfield's Bronze-Cuckoo has been recorded for all Australian fairy-wren species, as well as several emu-wren and grass-wren species (Brooker and Brooker 1989; Maguire and Mulder 2004).

Fairy-wrens are also secondary hosts of the Shining BronzeCuckoo (Chalcites lucidus), which primarily parasitises thornbills (Acanthiza spp.); the Brush Cuckoo (Cacomantis variolosus), which primarily parasitises flycatchers (Dicruridae), Ramsayornis honeyeaters and robins (Petroicidae), and the Fan-tailed Cuckoo (Cacomantis pyrrhophanus), which primarily parasitises scrubwrens (Sericornis spp.), thornbills and rockwarblers (Origma solitaria) (Brooker and Brooker 1989). There are also rare reports of parasitism of fairy-wrens by the Black-eared Cuckoo (C. osculans) and the Little BronzeCuckoo (C. minutillus) (Brooker and Brooker 1989). Parasitism of fairy-wrens by cuckoo species other than Horsfield's BronzeCuckoo occurs at extremely low rates (Table 1), suggesting high levels of host-specificity in Australian cuckoos (Brooker and Brooker 1992; Langmore and Kilner 2007). For example, long-term studies at three different study sites failed to find any parasitism by Shining Bronze-Cuckoos or Fan-tailed Cuckoos in several thousand fairy-wren nests, despite regular parasitism by these cuckoos of their primary hosts at the same sites (Brooker and Brooker 1992; Langmore and Kilner 2007). At sites where these cuckoo species did exploit fairy-wrens, parasitism rates were less than $2 \%$ (Table 1). Owing to the relatively low parasitism rates by these cuckoo species the 
Table 1. Exploitation of fairy-wrens as secondary hosts by Shining Bronze-Cuckoos, Fan-tailed Cuckoos and Brush Cuckoos Study site locations are shown in Fig. 2

\begin{tabular}{|c|c|c|}
\hline Cuckoo species and study site & Parasitism rates of primary hosts & Parasitism rates of fairy-wrens \\
\hline \multicolumn{3}{|l|}{ Shining Bronze-Cuckoo } \\
\hline Campbell Park, $\mathrm{ACT}^{\mathrm{A}}$ & $\begin{array}{l}\text { 17\% (78 Yellow-rumped Thornbill nests), } 12 \% \text { (97 Buff-rumped } \\
\text { Thornbill nests) }\end{array}$ & $0 \%$ (715 Superb Fairy-wren nests) \\
\hline Gooseberry Hill, $\mathrm{WA}^{\mathrm{B}}$ & $\begin{array}{l}\text { 32.1\% ( } 81 \text { Yellow-rumped Thornbill nests), 5.2\% (325 Western } \\
\text { Thornbill nests) }\end{array}$ & 0\% (519 Splendid Fairy-wren nests) \\
\hline \multicolumn{3}{|l|}{ Fan-tailed Cuckoo } \\
\hline $\begin{array}{l}\text { Australian National } \\
\text { Botanic Gardens, ACT }\end{array}$ & $\begin{array}{l}0.6 \%(157 \text { Brown Thornbill nests })^{\mathrm{C}}, 2.3 \% \text { (39 Brown Thornbill } \\
\text { nests })^{\mathrm{D}}, 4.7 \%(491 \text { White-browed Scrubwren nests })^{\mathrm{E}}\end{array}$ & $0 \%(2650 \text { Superb Fairy-wren nests })^{\mathrm{F}}$ \\
\hline $\begin{array}{l}\text { Smith Brook Reserve, } \\
\text { WA }(1980-86)^{\mathrm{G}}\end{array}$ & Not monitored & $0.7 \%$ (252 Red-winged Fairy-wren nests) \\
\hline $\begin{array}{l}\text { Smith Brook Reserve, } \\
\text { WA }(2008-11)^{\mathrm{H}}\end{array}$ & Not monitored & 1.4\% (447 Red-winged Fairy-wren nests) \\
\hline \multicolumn{3}{|l|}{ Brush Cuckoo } \\
\hline Near Brisbane, Qld ${ }^{\mathrm{I}}$ & Not monitored & $1.8 \%$ (221 Red-backed Fairy-wren nests) \\
\hline Mornington Sanctuary, $\mathrm{WA}^{\mathrm{J}}$ & Not monitored & $0.4 \%$ (489 Purple-crowned Fairy-wren nests) \\
\hline $\begin{array}{l}{ }^{\mathrm{A}} \text { Langmore and Kilner (2007). } \\
{ }^{\mathrm{B}} \text { Brooker and Brooker (1992). } \\
{ }^{\mathrm{C}} \text { Green and Cockburn (1999). } \\
{ }^{\mathrm{C}} \text { B. Igic, pers. comm. (2010-11 } \\
{ }^{\mathrm{E}} \text { R. Magrath, pers. comm. (1991 } \\
{ }^{\mathrm{F}} \text { A. Cockburn, pers. comm. (198 } \\
{ }^{\mathrm{G}} \text { Rowley et al. (1988). } \\
{ }^{\mathrm{H}} \text { L. Brouwer, pers. comm. (200 } \\
{ }^{\mathrm{I}} \text { D. T. Baldassarre and M. S. W } \\
{ }^{\mathrm{J}} \text { M. L. Hall and A. Peters, pers. }\end{array}$ & $\begin{array}{l}98) . \\
-2010) . \\
\text { 11). } \\
\text { ster, pers. comm. }(2010-11) \text {. } \\
\text { mm. (2006-10). }\end{array}$ & \\
\hline
\end{tabular}

remainder of this paper will focus on parasitism of malurids by Horsfield's Bronze-Cuckoos.

\section{Parasitism rates in the Maluridae}

The large number of current or recent studies on fairy-wrens provide a rare opportunity to compare annual parasitism rates in several concurrent studies (Table 2, Fig. 1). Several general conclusions can be drawn from comparison of parasitism rates at different study sites over several years (Fig. 1). First, parasitism rates vary dramatically. Almost all studies of all species showed marked annual fluctuations in parasitism rates. Second, the data do not reveal any national or regional annual trends in parasitism rates. For example, in five studies of Superb Fairy-wrens, parasitism rates in any one year differed dramatically between sites; the only point of similarity was that no sites were parasitised in 2010 (Fig. 1a). Third, even within a small geographical area parasitism rates may vary widely. For example, Superb Fairy-wren populations at two woodland sites $7 \mathrm{~km}$ apart in Canberra, Gungahlin Hill and Campbell Park, suffered 43 and $0 \%$ parasitism respectively in 2009 (Fig. 1). Similar levels of microgeographic variation in parasitism rate within and between years have been found in other cuckoo-host systems (e.g. Soler et al. 1998). Fourth, no fairy-wren populations suffered parasitism every year. This contrasts with studies of the Common Cuckoo (Cuculus canorus), where individual female cuckoos may return to the same breeding site year after year (Davies 2000). Unpredictable and highly variable parasitism is likely to have important consequences for the evolution of host defences against cuckoos (see Phenotypic Plasticity in Host
Defences, below). Finally, the data support previous suggestions that parasitism by Horsfield's Bronze-Cuckoos is relatively lower in Purple-crowned Fairy-wrens (M. coronatus) and Redwinged Fairy-wrens ( $M$. elegans) than in other fairy-wren species (Rowley et al. 1988), particularly Superb and Splendid (M. splendens) Fairy-wrens. The data also suggest that Bluebreasted Fairy-wrens (M. pulcherrimus), White-winged Fairywrens (M. leucopterus) and Red-backed Fairy-wrens (M. melanocephalus) are major hosts.

\section{Coevolution between malurids and bronze-cuckoos}

Coevolution between brood-parasitic cuckoos and their hosts can lead to a whole suite of defences in hosts and counteradaptations in cuckoos at every stage of the breeding cycle. Most host species exhibit defences at one or more of three stages: before the deposition of the cuckoo egg ('front-line' adaptations), the egg stage and the chick (nestling/fledgling) stage.

\section{Coevolution at the front line}

Many host species show a mobbing response when they see a cuckoo near their nest. Studies suggest that mobbing may be effective in preventing parasitism (Feeney et al. 2012), and can even cause injury (Davies and Brooke 1988) or death (Molnar 1944; Moyer 1980) to the parasite. Mobbing appears to be the main front-line defence of fairy-wrens. Like other host species, fairy-wrens approach and harass cuckoos in their territory. Group members unite in their efforts, producing loud, rapid calls. In experiments with preserved bronze-cuckoo specimens, both Splendid Fairy-wrens (Payne et al. 1985) and Superb Fairy-wrens 
Table 2. Summary of parasitism rates in Fairy-wrens

\begin{tabular}{|c|c|c|c|c|c|c|c|}
\hline Species and site & Years & $\begin{array}{l}\text { Nests } \\
\text { laid in }\end{array}$ & $\begin{array}{l}\text { Parasitised } \\
\text { by HBC }\end{array}$ & $\begin{array}{c}\text { Parasitised } \\
\text { by other } \\
\text { cuckoo }\end{array}$ & $\begin{array}{c}\mathrm{HBC} \\
\text { parasitism } \\
(\%)\end{array}$ & $\begin{array}{c}\text { Total } \\
\text { parasitism } \\
(\%)\end{array}$ & Source \\
\hline \multicolumn{8}{|l|}{ Red-backed Fairy-wren } \\
\hline Near Brisbane & $2010-2011$ & 221 & 11 & 5 (Brush) & 4.8 & 8.14 & $\begin{array}{l}\text { D. T. Baldassarre and } \\
\text { M. S. Webster, unpubl. data }\end{array}$ \\
\hline Moomin, Qld & 2004-2011 & 602 & 17 & 0 & 2.82 & 2.82 & $\begin{array}{l}\text { D. G. Barron and M. S. Webster, } \\
\text { unpubl. data }\end{array}$ \\
\hline Donkey Farm, Qld & 2004-2011 & 550 & 3 & 0 & 0.55 & 0.55 & $\begin{array}{l}\text { D. G. Barron and M. S. Webster, } \\
\text { unpubl. data }\end{array}$ \\
\hline Mornington Sanctuary, WA & 2007 & 59 & 12 & 0 & 20.34 & 20.34 & S. A. Murphy, unpubl. data \\
\hline \multicolumn{8}{|l|}{ Red-winged Fairy-wren } \\
\hline Smith’s Brook Reserve & $1980-1986$ & 117 & 3 & 2 (Fan-tailed) & 2.6 & 4.3 & Rowley et al. (1988) \\
\hline Smith's Brook Reserve & 2008-2011 & 447 & 9 & 2 (Fan-tailed) & 2 & 2.5 & L. Brouwer unpubl. data \\
\hline \multicolumn{8}{|l|}{ Superb Fairy-wren } \\
\hline $\begin{array}{l}\text { Australian National } \\
\text { Botanic Gardens, ACT }\end{array}$ & $1988-2010$ & $2650^{\mathrm{A}}$ & 29 & 0 & 1.1 & 1.1 & A. Cockburn, unpubl. data \\
\hline Campbell Park, ACT & 1999-2011 & 944 & 119 & 0 & 12.6 & 12.6 & $\begin{array}{l}\text { N. E. Langmore and R. M. Kilner, } \\
\text { unpubl. data }\end{array}$ \\
\hline Gungahlin Hill, ACT & $2007-2010$ & 69 & 18 & 0 & 25.6 & 25.6 & N. E. Langmore, unpubl. data \\
\hline Armidale, NSW & $1981-1986$ & 161 & $14^{\mathrm{B}}$ & 0 & 8.6 & 8.6 & Nias and Ford (1992) \\
\hline Serendip Sanctuary, Vic. & 2011 & 191 & 57 & 0 & 29.8 & 29.8 & $\begin{array}{l}\text { M. L. Hall and R. A. Mulder, } \\
\text { unpubl. data }\end{array}$ \\
\hline Fleurieu Peninsula, SA & $2003-2011$ & 156 & 5 & 0 & 3.2 & 3.2 & $\begin{array}{l}\text { D. Collombelli-Negrel and } \\
\text { S. Kleindorfer, unpubl. data }\end{array}$ \\
\hline \multicolumn{8}{|l|}{ Blue-breasted Fairy-wren } \\
\hline Wyalkatchem, WA & 1993-1998 & 254 & 57 & 0 & 22.4 & 22.4 & Brooker and Brooker (2003) \\
\hline Dryandra, WA & 1990-1999 & 160 & 13 & & 8.1 & 8.1 & Rowley and Russell (2002) \\
\hline \multicolumn{8}{|l|}{ Purple-crowned Fairy-wren } \\
\hline Mornington Sanctuary, WA & 2006-2010 & 489 & 4 & 2 (Brush) & 0.8 & 1.2 & $\begin{array}{l}\text { M. L. Hall and A. Peters, unpubl. } \\
\text { data }\end{array}$ \\
\hline \multicolumn{8}{|l|}{ Splendid Fairy-wren } \\
\hline Gooseberry Hill, WA & $1973-1988$ & 656 & 147 & 0 & 22.4 & 22.4 & Rowley et al. (1991) \\
\hline \multicolumn{8}{|l|}{ White-winged Fairy-wren } \\
\hline Near Lancelin, WA & $2000-2001$ & 51 & 1 & 0 & 2 & 2 & $\begin{array}{l}\text { Rathburn and Montgomerie } \\
\text { (2003) }\end{array}$ \\
\hline Dirk Hartog Island, WA & $2000-2001$ & 61 & 11 & 0 & 18 & 18 & $\begin{array}{l}\text { Rathburn and Montgomerie } \\
\text { (2003) }\end{array}$ \\
\hline \multicolumn{8}{|l|}{ Southern Emu-wren } \\
\hline Portland, Vic. & $2000-2002$ & $24^{\mathrm{A}}$ & 1 & 0 & 4.2 & 4.2 & Maguire and Mulder (2004) \\
\hline
\end{tabular}

${ }^{\mathrm{A}}$ Parasitism not monitored at egg stage, so overall number of nests containing chicks and number of cuckoo chicks are presented.

${ }^{\mathrm{B}}$ Assumed that cuckoo was Horsfield's Bronze-cuckoo, species not given in paper.

(Langmore et al. 2012) physically attacked the model, pecking and pulling at its feathers.

Fairy-wrens also show a front-line response that is thus far unique amongst cuckoo hosts. Both Splendid and Superb Fairywrens produce a rapid, high-energy, 'whining' call in response to cuckoos and cuckoo mounts (Payne et al. 1985; Langmore et al. 2012) and on-going work suggests that this is a referential call, given only in response to cuckoo mounts. To this extent, the call is analogous to the 'seet' call produced by Yellow Warblers (Dendroica petechia) in response to brood-parasitic Brownheaded Cowbirds (Molothrus ater) (Hobson and Sealy 1989; Gill and Sealy 2004). However, the two calls appear to be functionally distinct. In Yellow Warblers, playback of 'seet' calls stimulates the female to rush to sit on her nest (Gill and Sealy 2004). By contrast, in Superb Fairy-wrens, helper males approached cuckoo mounts only in those trials where whining calls were produced by the breeding pair (Langmore et al. 2012). This suggests that the whining call functions to 'rally the troops' for more effective mobbing of cuckoos. It would be interesting to discover how widespread the whining call is amongst the Maluridae. Given its specificity to cuckoos, we might expect that it would be absent from the vocal repertoire of the rarely parasitised malurids, such as Emu-wrens (Stipiturus spp.) and Lovely Fairy-wrens (M. amabilis) (although these species may be more frequent hosts than we realise - there are too few nest records to be sure).

\section{Coevolution at the egg stage}

The egg stage is the most well studied stage of coevolution between brood parasites and their hosts. Many host species have evolved the ability to detect and reject foreign eggs in their nests, 


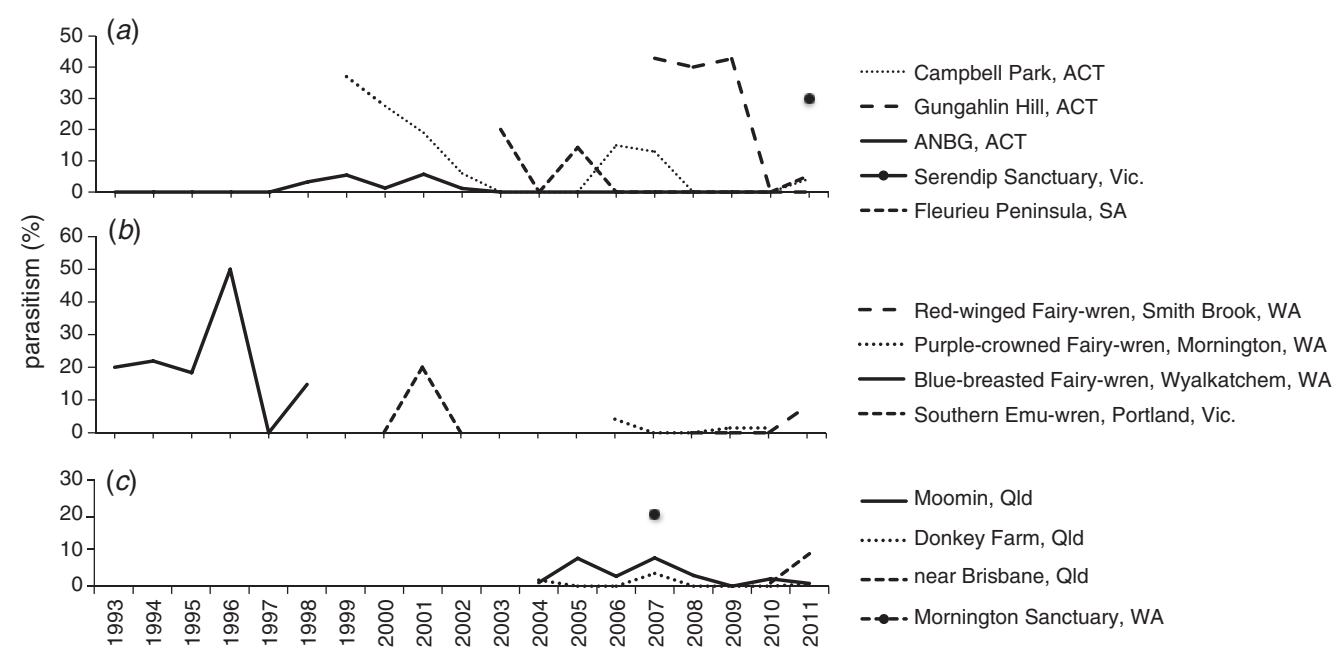

Fig. 1. Annual rates of parasitism by Horsfield's Bronze-Cuckoos on (a) Superb Fairy-wrens at five study sites, (b) Redwinged Fairy-wrens, Purple-crowned Fairy-wrens, Blue-breasted Fairy-wrens and Southern Emu-wrens at four different study sites and $(c)$ Red-backed Fairy-wrens at four study sites. See Table 2 for sources of data. Locations of study sites are shown in Fig. 2.

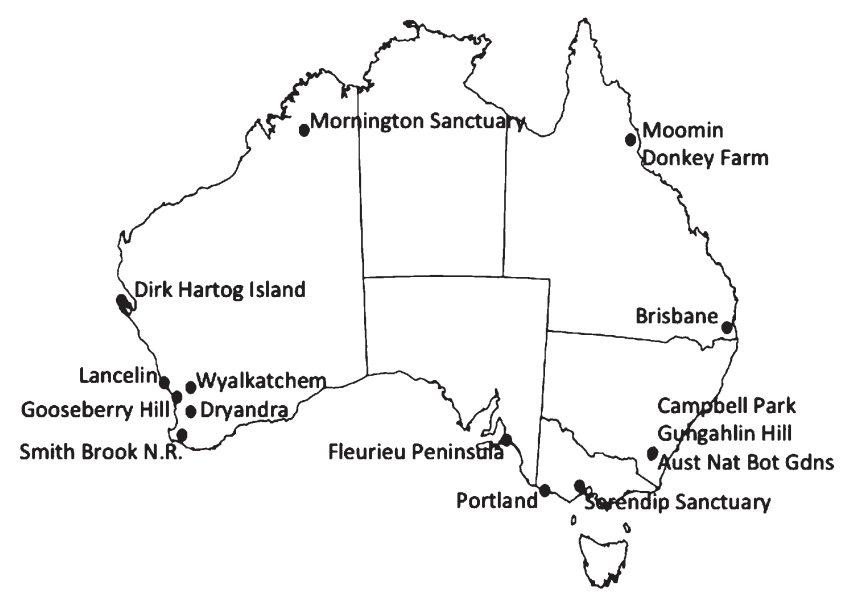

Fig. 2. Location of the study sites listed in Tables 1 and 2 and Fig. 1.

and this, in turn, selects for mimicry of host eggs by cuckoos. However, fairy-wrens and Horsfield's Bronze-Cuckoos present a conundrum: fairy-wrens show no evidence of rejection of either cuckoo eggs or model eggs that differ in colour or pattern from their own (Brooker and Brooker 1989; Langmore et al. 2003), yet Horsfield's Bronze-Cuckoos lay an egg that closely resembles fairy-wren eggs. This raises two questions about coevolution between Horsfield's Bronze-Cuckoos and fairywrens. First, why don't fairy-wrens reject cuckoo eggs, given that they are a primary host and suffer high rates of parasitism? Second, if fairy-wrens don't reject cuckoo eggs, why do cuckoos lay mimetic eggs, given that the accuracy of mimicry of host eggs by cuckoos usually reflects the degree of egg discrimination and rejection by hosts (Honza et al. 2004; Antonov et al. 2006; Stoddard and Stevens 2011)?

Addressing the first question, a likely explanation for the failure of fairy-wrens to reject cuckoo eggs is the poor visibility inside their dark, dome-shaped nests. Poor light availability is a widespread constraint on cuckoo egg rejection in dome-nesting hosts (Langmore et al. 2005, 2009b). Although fairy-wrens are constrained in the use of visual cues to recognise cuckoo eggs, they still display some egg stage defences through the use of other cues. Superb, Splendid, White-winged and Variegated (M. lamberti) Fairy-wrens bury any egg that appears before they have commenced egg laying (Brooker and Brooker 1989; Langmore et al. 2003). Superb Fairy-wrens also abandon nests if parasitised by a cuckoo after commencement of incubation or if their nest contains an egg that is substantially larger than their own (Langmore et al. 2003). This suggests that Horsfield's Bronze-Cuckoos are under selection for accurate timing of egg laying and for small egg size. Correspondingly, Horsfield's Bronze-Cuckoos lay over $68 \%$ of their eggs during the laying period of the host (Langmore et al. 2003), and lay a small egg for their body size (Krüger and Davies 2004).

There are several possible answers to the second question: how has egg mimicry evolved in the absence of egg rejection by hosts? One possibility is that the cuckoos themselves impose selection for mimetic eggs. If more than one female cuckoo parasitises the same nest, it would pay the second cuckoo to remove the existing cuckoo egg so that her own offspring is not evicted later by the first-laid cuckoo (Davies and Brooke 1988; Brooker and Brooker 1989; Brooker et al. 1990). If so, a female cuckoo should selectively remove the oddest-looking egg from the nest before adding her own, a process that would select for mimetic cuckoo eggs. However, in an experimental test using model eggs, Horsfield's Bronze-Cuckoo females were no more likely to remove a non-mimetic egg from a fairy-wren clutch than would be expected by chance (Langmore and Kilner 2009). Therefore, the puzzle of how egg mimicry evolved in Horsfield's Bronze-Cuckoos remains unresolved. Possible alternative explanations are that (1) host and cuckoo eggs resemble one another by chance alone (Grim 2005), (2) egg mimicry was selected by cuckoo discrimination in the past but this behaviour 
has now been lost, (3) egg mimicry was selected by a past host that has lost its egg-rejection behaviour or is no longer parasitised (Langmore and Kilner 2009) or (4) egg mimicry has been selected through an increased probability of cuckoo chick rejection if an odd egg appears in the nest (R. M. Kilner and N. E. Langmore, unpubl. data).

\section{Coevolution at the chick stage}

Despite the refined abilities of many hosts to detect tiny differences between their own and foreign eggs, most hosts show no comparable discrimination of cuckoo chicks. The failure of hosts to evolve cuckoo chick rejection has posed a major challenge to coevolutionary theory. Studies on the Maluridae have made substantial contributions towards resolving this paradox.

The Superb Fairy-wren was the first cuckoo host to be identified as a cuckoo chick rejecter (Langmore et al. 2003). Approximately $40 \%$ of Superb Fairy-wren breeding groups cease feeding the cuckoo 2-6 days after hatching and abandon it to die in the nest (Langmore et al. 2003). The evolution of chick-stage defences in Superb Fairy-wrens was attributed to the relatively poor defences at the egg stage in this species, owing to limited visibility inside their dome-shaped nests (Langmore et al. 2003, 2005). Since then, other hosts with dome-shaped nests have also been found to reject brood-parasite chicks (Sato et al. 2010; Tokue and Ueda 2010; Delhey et al. 2011).

In response to discrimination by hosts, cuckoo chicks have evolved striking visual mimicry of host young (Langmore et al. 2011). They also mimic the begging calls of their primary host and, when reared by a secondary host, they can even modify the structure of their begging call to match that of the secondary host (Langmore et al. 2008). Despite such sophisticated mimicry, one population of fairy-wrens appears to have evolved a way of detecting the imposter by its calls. In a population of Superb Fairy-wrens in South Australia, females produce an individually distinctive incubation call to their eggs, and upon hatching the nestlings produce begging calls with key elements of their mother's call (Colombelli-Négrel et al. 2012). Adults reduce provisioning in response to playback of the wrong call. However, in a different Superb Fairy-wren population the primary cue for rejection was having a lone chick in the nest, and females were just as likely to abandon their own chick if it was alone in the nest as they were to abandon a cuckoo chick (Langmore et al. 2003), indicating that a password was not the basis for rejection decisions.

The evidence that fairy-wrens display chick rejection but not egg rejection, whereas many other hosts show egg rejection but not chick rejection, prompted the development of a new model to explain the evolution of host defence portfolios (Britton et al. 2007). Britton et al. (2007) extended the work of Dawkins (1982), who argued that because there are costs involved in any adaptation, it is not advantageous to develop a defence against a rare enemy. Britton et al. (2007) suggested that although cuckoos are not a rare enemy, if a defence at one stage of the breeding cycle is so successful that a cuckoo is rarely encountered at later stages, there will be little selection for defences at later stages due to the diminishing returns. This model elegantly explains the lack of chick rejection in many cuckoo hosts. Britton's theoretical model has, in turn, prompted significant interest in how the evolution of one defence may influence the evolution of other defences, leading to different coevolutionary trajectories in different host-parasite systems (Kilner and Langmore 2011).

\section{Phenotypic plasticity in host defences}

The relative costs and benefits to hosts of expressing defences against cuckoos are likely to vary depending on the probability of parasitism. Not surprisingly, then, many hosts modify the expression of defences in relation to the risk of parasitism (Davies et al. 1996; Langmore et al. 2009a; Welbergen and Davies 2009). For example, hosts may adjust the intensity of their mobbing response (if mobbing carries costs) (Welbergen and Davies 2009) or their rejection threshold for eggs (Davies and Brooke 1988; Moksnes and Røskaft 1989; Moksnes et al. 1993; Alvarez 1996; Davies et al. 1996; Bártol et al. 2002; Soler et al. 2012) according to the probability of being parasitised. Suppression of defence behaviour in years when cuckoos are absent minimises the likelihood of costly recognition errors, such as rejection of the host's own eggs or chicks. Phenotypic plasticity in defences is likely to be particularly beneficial to fairy-wrens, which experience such dramatically varying parasitism rates from one year to the next (Fig. 1). In line with this prediction, Superb Fairy-wrens reject cuckoo chicks only in years where cuckoos are present in the population, thereby minimising the risk of mistakenly rejecting their own young (Langmore et al. 2009a).

\section{Challenges for the future}

Much progress has been made in understanding the defences of Superb and Splendid Fairy-wrens against brood parasitism and their interactions with cuckoos in the nest. The cuckoos themselves are more enigmatic than their hosts, and much less is known about cuckoo counter-strategies to host defences. For example, are the highly variable parasitism rates at any one site (Fig. 1) the outcome of cuckoo movements in relation to fluctuating environmental variables, or are they a strategy to maximise interactions with 'naïve' fairy-wrens who have not encountered cuckoos in the past and are therefore less likely to express defences (Langmore et al. 2009a, 2012)? Similarly, we know that individual female cuckoos show a transitory breeding pattern, remaining on a breeding site for just a few weeks (Langmore et al. 2007). Is this because the female has saturated available host nests, or perhaps so that the cuckoo can reduce the chances of detection by hosts and thereby decrease the probability that hosts will express defences such as cuckoo chick rejection?

The evolution of Horsfield's Bronze-Cuckoo egg and chick morphology are also of interest. Many other cuckoo species exhibit host-specific races, each of which lays an egg that matches its favoured host (Gibbs et al. 2000). However, Horsfield's Bronze-Cuckoos show no evidence of host-specific races (Joseph et al. 2002; Langmore et al. 2008) and their eggs appear to be monomorphic. Does this reflect a general lack of egg discrimination in hosts, or has the cuckoo evolved to parasitise only those hosts with eggs similar enough to its own that egg rejection is rare? At the chick stage, Horsfield's BronzeCuckoos are excellent vocal mimics of host nestlings (Langmore et al. 2008), yet only imperfect visual mimics (Langmore et al. 
2012). Are there unidentified constraints on the evolution of visual mimicry, or has the cuckoo chick evolved a morphology that is intermediate between that of several different hosts, so as to maximise the chances of duping several different host species (Langmore et al. 2011)?

We also know very little about the interactions between other species of malurids and cuckoos. It would be interesting to know the extent of the coevolutionary arms race in those species that experience lower parasitism rates than Splendid and Superb Fairy-wrens: is the arms race less advanced because parasitism is rare, or are low parasitism rates the outcome of better defences in these species? Finally, some fairy-wrens are hosts to other, larger cuckoo species in addition to Horsfield's Bronze-Cuckoo. The costs of parasitism may be higher when parasitised by these cuckoos, potentially leading to different evolutionary trajectories in the coevolutionary arms race between cuckoos and their hosts.

These are just a few of the interesting possibilities for future research on cuckoo parasitism in the Maluridae. The group has already made significant contributions to understanding brood parasitism and coevolution, particularly in launching a new line of research into coevolution at the chick stage. Many puzzles still remain in the study of cuckoo-host coevolution and the Maluridae provide a superb, even splendid, opportunity to tackle them!

\section{Acknowledgements}

Warmest thanks to Daniel Baldasarre, Doug Barron, Lyanne Brouwer, Andrew Cockburn, Diane Collombelli-Negrel, Michelle Hall, Brani Igic, Sonia Kleindorfer, Rob Magrath, Raoul Mulder, Steve Murphy, Anne Peters and Mike Webster for generously providing data on annual parasitism rates from their long-term datasets, and to Rob Heinsohn and two reviewers for helpful comments on the manuscript. This work was supported by an Australian Research Council Discovery Grant.

\section{References}

Alvarez, F. (1996). Model Cuckoo Cuculus canorus eggs accepted by Rufous Bush Chats Cercotrichas galactotes during the parasite's absence from the breeding area. Ibis 138, 340-342. doi:10.1111/j.1474-919X. 1996.tb04349.x

Antonov, A., Stokke, B. G., Moksnes, A., and Røskaft, E. (2006). Egg rejection in Marsh Warblers (Acrocephalus palustris) heavily parasitized by Common Cuckoos (Cuculus canorus). Auk 123, 419-430. doi:10.1642/0004-8038(2006)123[419:ERIMWA]2.0.CO;2

Bártol, I., Karcza, Z., Moskát, C., Røskaft, E., and Kisbenedek, T. (2002). Responses of Great Reed Warblers Acrocephalus arundinaceus to experimental brood parasitism: the effects of a Cuckoo Cuculus canorus dummy and egg mimicry. Journal of Avian Biology 33, 420-425. doi:10.1034/j.1600-048X.2002.02945.x

Britton, N. F., Planque, R., and Franks, N. R. (2007). Evolution of defence portfolios in exploiter-victim systems. Bulletin of Mathematical Biology 69, 957-988. doi:10.1007/s11538-006-9178-5

Brooker, M. G., and Brooker, L. C. (1989). Cuckoo hosts in Australia. Australian Zoological Reviews 2, 1-67.

Brooker, M., and Brooker, L. (1992). Evidence for individual female host specificity in two Australian bronze-cuckoos (Chrysococcyx spp.). Australian Journal of Zoology 40, 485-493. doi:10.1071/ZO9920485

Brooker, M., and Brooker, L. (1996). Acceptance by the Splendid Fairywren of parasitism by Horsfield's Bronze Cuckoo: further evidence for evolutionary equilibrium in brood parasitism. Behavioral Ecology 7, 395-407. doi:10.1093/beheco/7.4.395

Brooker, M., and Brooker, L. (2003). Brood parasitism by Horsfield's Bronze-Cuckoo in a fragmented agricultural landscape in Western Australia. Ети 103, 357-361. doi:10.1071/MU02034

Brooker, L. C., Brooker, M. G., and Brooker, A. M. H. (1990). An alternative population/genetics model for the evolution of egg mimesis and egg crypsis in cuckoos. Journal of Theoretical Biology 146, 123-143.

Colombelli-Négrel, D., Hauber, M. E., Robertson, J., Sulloway, F. J., Hoi, H., Griggio, M., and Kleindorfer, S. (2012). Embryonic learning of vocal passwords in Superb Fairy-wrens reveals intruder cuckoo nestlings. Current Biology 22, 2155-2160. doi:10.1016/j.cub.2012.09.025

Davies, N. B. (2000). 'Cuckoos, Cowbirds and other Cheats.' (T \& A D Poyser: London.)

Davies, N. B., and Brooke, M. L. (1988). Cuckoos versus reed warblers: adaptations and counteradaptations. Animal Behaviour 36, 262-284. doi:10.1016/S0003-3472(88)80269-0

Davies, N. B., Brooke, M. L., and Kacelnik, A. (1996). Recognition errors and probability of parasitism determine whether reed warblers should accept or reject mimetic cuckoo eggs. Proceedings of the Royal Society of London - B. Biological Sciences 263, 925-931. doi:10.1098/rspb. 1996.0137

Dawkins, R. (1982). 'The Extended Phenotype: the Long Reach of the Gene.' (Oxford University Press: Oxford, UK.)

Delhey, K., Carrizo, M., Verniere, L., Mahler, B., and Peters, A. (2011). Rejection of brood-parasitic Shiny Cowbird Molothrus bonariensis nestlings by the Firewood-gatherer Anumbius annumbi? Journal of Avian Biology 42, 463-467. doi:10.1111/j.1600-048X.2011.05439.x

Feeney, W. E., Welbergen, J. A., and Langmore, N. E. (2012). The frontline of avian brood parasite-host coevolution. Animal Behaviour 84, 3-12.

Gibbs, H. L., Sorenson, M. D., Marchetti, K., Brooke, M. D., Davies, N. B., and Nakamura, H. (2000). Genetic evidence for female host-specific races of the Common Cuckoo. Nature 407, 183-186. doi:10.1038/ 35025058

Gill, S. A., and Sealy, S. G. (2004). Functional reference in an alarm signal given during nest defence: seet calls of Yellow Warblers denote brood parasitic Brown-headed Cowbirds. Behavioral Ecology and Sociobiology 56, 71-80. doi:10.1007/s00265-003-0736-7

Green, D. J., and Cockburn, A. (1999). Life history and demography of an uncooperative Australian passerine, the Brown Thornbill. Australian Journal of Zoology 47, 633-649. doi:10.1071/ZO99052

Grim, T. (2005). Mimicry vs. similarity: which resemblances between brood parasites and their hosts are mimetic and which are not? Biological Journal of the Linnean Society. Linnean Society of London 84, 69-78. doi:10.1111/j.1095-8312.2005.00414.x

Hobson, K. A., and Sealy, S. G. (1989). Responses of Yellow Warblers to the threat of cowbird parasitism. Animal Behaviour 38, 510-519. doi:10.1016/S0003-3472(89)80044-2

Honza, M., Prochazka, P., Stokke, B. G., Moksnes, A., Røskaft, E., Capek, M., and Mrlik, V. (2004). Are Blackcaps current winners in the evolutionary struggle against the Common Cuckoo? Journal of Ethology 22, 175-180. doi:10.1007/s10164-004-0119-1

Joseph, L., Wilke, T., and Alpers, D. (2002). Reconciling genetic expectations from host specificity with historical population dynamics in an avian brood parasite, Horsfield's Bronze-Cuckoo Chalcites basalis of Australia. Molecular Ecology 11, 829-837. doi:10.1046/j.1365-294X. 2002.01481.x

Kilner, R. M., and Langmore, N. E. (2011). Cuckoos versus hosts in insects and birds: adaptations, counter-adaptations and outcomes. Biological Reviews of the Cambridge Philosophical Society 86, 836-852. doi:10.1111/j.1469-185X.2010.00173.x

Krüger, O., and Davies, N. B. (2004). The evolution of egg size in the brood parasitic cuckoos. Behavioral Ecology 15, 210-218. doi:10.1093/ beheco/arg104 
Langmore, N. E., and Kilner, R. M. (2007). Breeding site and host selection by Horsfield's Bronze-Cuckoos, Chalcites basalis. Animal Behaviour 74, 995-1004. doi:10.1016/j.anbehav.2007.02.028

Langmore, N. E., and Kilner, R. M. (2009). Why do Horsfield's Bronze-Cuckoo Chalcites basalis eggs mimic those of their hosts? Behavioral Ecology and Sociobiology 63, 1127-1131. doi:10.1007/s00265-009-0759-9

Langmore, N. E., Hunt, S., and Kilner, R. M. (2003). Escalation of a coevolutionary arms race through host rejection of brood parasitic young. Nature 422, 157-160. doi:10.1038/nature 01460

Langmore, N. E., Kilner, R. M., Butchart, S. H. M., Maurer, G., Davies, N. B., Cockburn, A., MacGregor, N. A., Peters, A., Magrath, M. J. L., and Dowling, D. K. (2005). The evolution of egg rejection by cuckoo hosts in Australia and Europe. Behavioral Ecology 16, 686-692. doi:10.1093/ beheco/ari041

Langmore, N. E., Adcock, G., and Kilner, R. M. (2007). The spatial organization and mating system of Horsfield's Bronze-Cuckoos, Chalcites basalis. Animal Behaviour 74, 403-412. doi:10.1016/j.anbehav.2006. 09.019

Langmore, N. E., Maurer, G., Adcock, G. J., and Kilner, R. M. (2008). Socially acquired host-specific mimicry and the evolution of host races in Horsfield's Bronze-Cuckoo Chalcites basalis. Evolution 62, 1689-1699. doi:10.1111/j.1558-5646.2008.00405.x

Langmore, N. E., Cockburn, A., Russell, A. F., and Kilner, R. M. (2009a). Flexible cuckoo chick rejection rules in the Superb Fairy-wren. Behavioral Ecology 20, 978-984. doi:10.1093/beheco/arp086

Langmore, N. E., Stevens, M., Maurer, G., and Kilner, R. M. (2009b). Are dark cuckoo eggs cryptic in host nests? Animal Behaviour 78, 461-468. doi:10.1016/j.anbehav.2009.06.003

Langmore, N. E., Stevens, M., Maurer, G., Heinsohn, R., Hall, M. L., Peters, A., and Kilner, R. M. (2011). Visual mimicry of host nestlings by cuckoos. Proceedings of the Royal Society of London - B. Biological Sciences 278, 2455-2463. doi:10.1098/rspb.2010.2391

Langmore, N. E., Feeney, W. E., Crowe-Riddell, J., Luan, H., Louwrens, K. M., and Cockburn, A. (2012). Learned recognition of brood parasitic cuckoos in the Superb Fairy-wren Malurus cyaneus. Behavioral Ecology 23, 798-805. doi:10.1093/beheco/ars033

Maguire, G. S., and Mulder, R. A. (2004). Breeding biology and demography of the Southern Emu-wren (Stipiturus malachurus). Australian Journal of Zoology 52, 583-604. doi:10.1071/ZO04043

Moksnes, A., and Røskaft, E. (1989). Adaptations of Meadow Pipits to parasitism by the Common Cuckoo. Behavioral Ecology and Sociobiology 24, 25-30. doi:10.1007/BF00300114

Moksnes, A., Røskaft, E., and Korsnes, L. (1993). Rejection of Cuckoo (Cuculus canorus) eggs by Meadow Pipits (Anthus pratensis). Behavioral Ecology 4, 120-127. doi:10.1093/beheco/4.2.120

Molnar, B. (1944). The cuckoo in the Hungarian plain. Aquila 51, 100-112.
Moyer, D. C. (1980). On Lesser Honeyguide and Black-collared Barbet. Zambian Ornithological Society Newsletter 10, 159.

Nias, R. C., and Ford, H. A. (1992). The influence of group-size and habitat on reproductive success in the Superb Fairy-wren Malurus cyaneus. Emu 92, 238-243. doi:10.1071/MU9920238

Payne, R. B., Payne, L. L., and Rowley, I. (1985). Splendid wren Malurus splendens response to cuckoos: an experimental test of social organization in a communal bird. Behaviour 94, 108-126. doi:10.1163/156853985X00299

Rathburn, M. K., and Montgomerie, R. (2003). Breeding biology and social structure of White-winged Fairy-wrens (Malurus leucopterus): comparison between island and mainland subspecies having different plumage phenotypes. Ети 103, 295-306. doi:10.1071/MU03011

Rothstein, S. I. (1990). A model system for coevolution: avian brood parasitism. Annual Review of Ecology and Systematics 21, 481-508. doi:10.1146/annurev.es.21.110190.002405

Rowley, I., and Russell, E. (2002). A population study of the Blue-breasted Fairy-wren, Malurus pulcherrimus, at Dryandra, Western Australia. Emu 102, 127-135. doi:10.1071/MU01059

Rowley, I., Russell, E., Brown, R., and Brown, M. (1988). The ecology and breeding biology of the Red-winged Fairy-wren Malurus elegans. Emu 88, 161-176. doi:10.1071/MU9880161

Rowley, I., Brooker, M., and Russell, E. (1991). The breeding biology of the Splendid Fairy-wren Malurus splendens: the significance of multiple broods. Ети 91, 197-221. doi:10.1071/MU9910197

Sato, N. J., Tokue, K., Noske, R. A., Mikami, O. K., and Ueda, K. (2010). Evicting cuckoo nestlings from the nest: a new anti-parasitism behaviour. Biology Letters 6, 67-69. doi:10.1098/rsbl.2009.0540

Soler, M., Soler, J. J., Martinez, J. G., Perez-Contreras, T., and Møller, A. P. (1998). Micro-evolutionary change and population dynamics of a brood parasite and its primary host: the intermittent arms race hypothesis. Oecologia 117, 381-390. doi:10.1007/s004420050671

Soler, M., Martin-Vivaldi, M., and Fernandez-Morante, J. (2012). Conditional response by hosts to parasitic eggs: the extreme case of the Rufoustailed Scrub robin. Animal Behaviour 84, 421-426. doi:10.1016/j. anbehav.2012.05.016

Stoddard, M. C., and Stevens, M. (2011). Avian vision and the evolution of egg color mimicry in the Common Cuckoo. Evolution 65, 2004-2013. doi:10.1111/j.1558-5646.2011.01262.x

Tokue, K., and Ueda, K. (2010). Mangrove Gerygones Gerygone laevigaster eject Little Bronze-Cuckoo Chalcites minutillus hatchlings from parasitized nests. Ibis 152, 835-839. doi:10.1111/j.1474-919X.2010. 01056.x

Welbergen, J. A., and Davies, N. B. (2009). Strategic variation in mobbing as a front line of defense against brood parasitism. Current Biology 19, 235-240. doi:10.1016/j.cub.2008.12.041 